\title{
Leveling the Playing Field: How Cold-Calling Affects Class Discussion Gender Equity
}

\author{
Elise J. Dallimore ${ }^{1}$, Julie H. Hertenstein ${ }^{2} \&$ Marjorie B. Platt ${ }^{2}$ \\ ${ }^{1}$ College of Art Media and Design, Northeastern University, Boston, Massachusetts, US \\ ${ }^{2}$ D’Amore-McKim School of Business, Northeastern University, Boston, Massachusetts, US \\ Correspondence: Marjorie B. Platt, Northeastern University, 404 Hayden Hall, 360 Huntington Ave., Boston \\ MA 02115 US. Tel: 1-617-373-4647.E-mail: m.platt@northeastern.edu
}

\author{
Received: February 3, $2019 \quad$ Accepted: February 22, $2019 \quad$ Online Published: February 25, 2019 \\ doi:10.5539/jel.v8n2p14 URL: https://doi.org/10.5539/jel.v8n2p14
}

\begin{abstract}
Classroom discussion is widely used and highly valued for actively engaging students in their own learning. A recent study has shown that cold-calling increases the number of students who participate voluntarily in class discussions and does not make them uncomfortable when doing so (Dallimore, Hertenstein, \& Platt, 2013). However, there are concerns about whether these findings generally apply to both men and women students since prior research has documented lower participation rates and higher discomfort for women.

This study examines the relationship between cold-calling and a) voluntary participation of both men and women students and b) student comfort participating in class discussions. The results show that cold-calling increases the percentage of both men and women who participate voluntarily. Further, the results indicate in high cold-calling classes women answer the same number of volunteer questions as men. Additionally, increased cold-calling did not make either group uncomfortable. However, differences were observed between men and women in low cold-calling environments where women answered fewer questions than men. Thus, cold-calling may help improve the performance of both men and women in class discussions and may make the classroom environment more equitable for women.
\end{abstract}

Keywords: class discussion, gender equity, student participation, cold-calling, comfort participating

\section{Introduction}

When discussion teaching is utilized, evidence suggests the more often students participate, the more they learn (Dallimore, Hertenstein, \& Platt, 2010; Morford, 2009). Therefore, one way instructors may help students learn is to ensure their discussion participation. However, most instructors would agree that getting all students to participate can be difficult. Students' hesitancy to participate ranges from shyness to cultural norms to lack of preparation. In a recent study, cold-calling, or calling on a student whose hand is not raised, is shown to increase voluntary participation in class discussion (Dallimore et al., 2013). Dallimore et al. (2013) further provides evidence that contrary to fears expressed by some authors (for example, Rocca (2010)) cold-calling does not necessarily make students uncomfortable. However, Dallimore et al. (2013) did not examine whether cold-calling affected women in the same way as men. This study goes beyond Dallimore et al. (2013) by focusing not on whether cold-calling is effective in encouraging students to more actively engage in class discussion, but rather on how cold-calling differentially affects men versus women students' class participation.

Prior studies have documented differences between women and men in class participation. These studies note that women participate less frequently than men (see, for example, Sadker \& Sadker (1994); Tatum, Schwartz, Schimmoeller, \& Perry (2013)), still experience “"chilly” behaviors from their male peers" (Allan \& Madden, 2006), and may be less comfortable participating (Micari \& Drane, 2011). These differences raise concerns that cold-calling might make women uncomfortable.

The study reported here examines the impact of cold-calling on the voluntary participation of men and women students and on their comfort participating in class discussions. Results find that in class environments with high cold-calling: (a) more men and women participate, and (b) women answer the same number of volunteer questions as men. Further, men and women respond similarly to cold-calling from the perspective of their comfort participating; that is, increased cold-calling did not make either group uncomfortable. 
On the contrary, in the class environments where little cold-calling was used women volunteered to answer fewer questions than did men. This evidence is consistent with prior literature on men and women in the classroom. It appears that when little cold-calling is used, prior expectations and behaviors regarding class participation continue. However, greater use of cold-calling may signal that all students are expected to participate and the contributions of all are valued, resulting in women's participation on par with men's.

These results make important contributions to the discussion teaching and cold-calling literature. They also contribute to the literature on gender differences in the classroom. We first review the literature on class discussion and learning, then gender and the classroom, strategies for increasing participation, and finally the emerging literature on the effects of cold-calling when encouraging participation. We next present our research hypotheses, methodology, and results, followed by our discussion and implications. After acknowledging this study's limitations and suggesting future research topics, we provide our concluding remarks.

\section{Literature Review}

\subsection{Discussion Participation Leads to Learning}

Discussion participation can enhance student learning (Dallimore et al., 2010; Fritschner, 2000; Weaver \& Qi, 2005 ) including providing students opportunities to develop and practice essential skills such as organizing concepts, formulating arguments, evaluating evidence, and responding to ideas thoughtfully and critically (Davis, 2009). Additionally, it allows students to experience a realistic context (Liang \& Wang, 2004) and master the language and thinking of a discipline (Krupnick, 1985). Discussion participation enables students to better retain information and elicits higher-level reflective thinking (Ewens, 2000), critical thinking (Tsui, 2002), and problem solving (Gilmore \& Schall, 1996).

\subsection{Gender Differences in Class Participation}

Prior studies have shown women students participate less frequently than men (see, for example, Allan \& Madden, (2006); Colbeck, Cabrera, \& Terenzini (2001); Tatum et al. (2013)). Hall's foundational research (1982) notes, “... it has come to be taken for granted by many faculty and students alike that men will usually dominate the discussion in college classrooms ..." (p. 7). Further, the tendency for women to remain silent may increase over time. Sadker and Sadker indicate, "Women's silence is loudest at college, with twice as many females voiceless." (1994, p. 170). The cumulative effect of teachers' behaviors toward women and men students from grade school through postgraduate studies are believed, at least in part, to be responsible for the gender differences in class participation (Allan \& Madden, 2006; Hall, 1982; Sadker \& Sadker, 1994).

In addition to research suggesting men speak more, recent evidence suggests men are more comfortable participating than women (Micari \& Drane, 2011). There is also evidence that women at the university-level may have higher communication apprehension than men (Coetzee, Schmulian, \& Kotze, 2014; Donovan \& MacIntyre, 2004). It is not clear, however, whether these differences are because women are inherently less comfortable or whether. they may result from factors such as past differences in treatment and fewer opportunities to participate.

In order to treat women and men students equitably, instructors are encouraged to make special efforts to draw women into the discussion, particularly early in the course when participation patterns are likely established (Fritschner, 2000; Hall, 1982) and to treat students equitably including: listen to all students with equal seriousness; challenge, correct and praise all students, and ask all students the same kinds of questions (Krupnick, 1985). Instructors are specifically encouraged to call on all students directly even if they don't raise their hands (Dallimore et al., 2013; Hall, 1982; Krupnick, 1985).

\subsection{Increasing Participation}

Many suggestions have been made about how to increase the number of students who volunteer to participate. For example, it has been suggested that instructors encourage all students to participate (Davis, 2009), set clear expectations about participation (Scollon \& Bau, 1981) and provide participation feedback and evaluation rubrics (Arter \& McTighe, 2001; Stevens \& Levi, 2005). More recently, there has been increasing discourse on the use of technology in teaching (Beekes, 2006; Quinn, 2010) which may increase student participation (Carnaghan \& Webb, 2007; Cunningham, 2008). While these techniques may increase the number of students who volunteer, not all students participate voluntarily (Sadker \& Sadker, 1994).

\subsection{Effects of Cold-calling on Student Discussion Participation}

A recent study suggests cold-calling provides a means to increase voluntary participation (Dallimore et al., 2013); however, the researchers did not examine whether cold-calling affected women the same way it affected men. Despite the fact that cold-calling provides a means to increase voluntary participation, some authors express 
concern with its use, fearing it will be anxiety-provoking and make students uncomfortable (Felder \& Brent, 2008; Rocca, 2010; Weimer, 2009). Dallimore et al. (2013) provide further evidence that cold-calling does not make students uncomfortable. However, especially because the majority of the students in their sample were men, the responses of women may have been concealed. Given the recommendations that all students be treated equally, an examination of whether cold-calling affects women the same way as men is needed.

\section{Research Hypotheses}

One characteristic of student participation in class discussions is the percentage of students who participate. Cold-calling has been shown to increase the percentage of students who participate voluntarily in class discussions (Dallimore et al., 2013). However as previously discussed differences have been noted in the number of women participants compared to the number of men; in general, we expect women students may respond differently to the use of cold-calling than men.

H1: Cold-calling affects the percentage of men who answer questions voluntarily differently than it affects the percentage of women.

Another characteristic of student participation is frequency or the number of times a student participates. Dallimore et al. (2013) found the frequency of students' voluntary participation was greater in classes where cold-calling was used often. However, again considering the previously discussed participation differences between men and women generally, we expect the frequency of women's participation may differ from men's when cold-calling is used often.

H2: Cold-calling affects men's participation frequency differently than it affects women's.

There is long-standing concern (Hall, 1982) and evidence (Micari \& Drane, 2011) that women are uncomfortable speaking in class. Further, as previously discussed, some authors have suggested cold-calling might make any student uncomfortable. Despite the fact that Dallimore et al. (2013) found cold-calling did not make students uncomfortable, it is possible cold-calling might have a different effect on women's comfort than on men's.

H3: Cold-calling affects women's comfort participating in class discussions differently than it affects men's.

\section{Method}

The quasi-experimental research design involved gathering both observation and survey data from students in a required undergraduate managerial accounting course at a major, private university. This course is ideally suited to examine how women and men students differ in their classroom participation behavior as well as attitudes towards class discussion because there are about equal women in undergraduate business educational programs generally as compared to men. (Note 1)

\subsection{Course and Instructors}

Managerial accounting develops quantitative as well as logic and strategic reasoning skills. The required managerial accounting course is typically taken by students in the beginning of their sophomore year; each section tends to have about 40 students. All sections of the course were "managed" such that students had a common experience. Instructors used the same text book and taught similar topics, but used their own pedagogy and materials.

Seven full-time instructors taught the course sections included in this study. Six were tenured or tenure-track and one was a full-time lecturer. Based on student ratings of teaching effectiveness and "treats students with respect," all instructors were considered strong teachers who provided a supportive environment in the classroom. Average teaching effectiveness ratings were 4.51 and average respect ratings were 4.64 on five-point scales.

The study rationale or research hypotheses were not discussed with the instructors. We did not actively control instructor's use of cold-calling. Variations in whether, or how much, instructors cold-called students were due to their natural instructional style.

\subsection{Data}

Two types of data were collected and integrated to create a common dataset. A pre-course survey was administered in the first two weeks of the course, followed by two observation periods in weeks 6-7 and 9-10 during which students discussed two different business cases. Finally, a post-course survey was administered during the last two weeks of the course.

\subsubsection{Surveys}

The pre-course survey gathered data on students' attitudes and behaviors related to class participation in courses prior to the managerial accounting course. The post-course survey focused on students' attitudes and behaviors 
related to class participation in the managerial accounting course. The Appendix contains questions analyzed in this study from both surveys. Demographic data including gender were also collected.

\subsubsection{Observations}

Specific class sessions were selected for observation because the session was devoted to a business case discussion. One graduate student was assigned to each class session as an observer. Observers were trained to categorize questions and record data. Following initial training, practice sessions were repeated until observers achieved consistency in coding. Research hypotheses were not discussed with the observers.

On a seating chart, observers noted the gender and seat location of each student at the beginning of each class session. For each question asked, the observer noted whether the instructor called on a volunteer or cold-called a student and recorded which student responded.

\subsection{Student Sample}

Using the last four digits of student identification numbers, pre-course and post-course surveys were matched for 359 students. The number of students present for the first and second observation periods were 578 and 559 , respectively. Approximately the same proportion of men $(54 \%)$ and women $(46 \%)$ survey respondents were present during the two class periods observed.

\subsection{Data Analysis}

\subsubsection{Independent Variables}

\subsubsection{Gender}

Men students were coded as zero (0), and women were coded as one (1).

\subsubsection{Cold-Call Environment}

This study's prime focus is to assess gender differences in student behavior during class discussions as well as students' perceptions about class discussions in differing cold-call environments. Based on observations of the percentage of students cold-called during the first class discussion, we categorized sections into two groups separated at the mean percentage of students cold-called, $26 \%$. The percentage of students cold-called in the high cold-calling (Hi CC) sections ranged from $33 \%$ to $84 \%$; by contrast, the percentage of students cold-called in the low cold-calling (Lo CC) sections ranged from $0 \%$ to $24 \%$. This categorization scheme resulted in five sections (196 students) rated as Hi CC and eleven sections (486 students) as Lo CC.

\subsubsection{Observation Period}

Because we could not identify the particular student sitting in each seat for each class discussion, the two observation periods were treated as between subject measures.

\subsubsection{Dependent Variables - Observation Data}

\subsubsection{Voluntary Student Participation}

Within each observation period, if a student answered at least one volunteer question, we recorded a 1 for that student on the "answered a voluntary question" variable; otherwise, we recorded a 0 . The percent of men and women present who answered at least one volunteer question was calculated for each section.

\subsubsection{Participation Frequency per Student}

To measure the frequency of voluntary participation at the individual student level, the number (count) of volunteer questions answered by each student present was recorded.

\subsubsection{Dependent Variables - Survey Data}

The pre-course survey questions focused on individual students' attitudes about class discussion as well as their own prior class discussion behavior. The post-course survey data focused on students' self-reported class participation as well as their attitudes and perceptions of their own and other students' class participation.

\subsection{Statistical Analysis}

Gender differences in student behavior and perceptions of class discussion between the two cold-call environments were analyzed using both univariate and multivariate analyses. 


\section{Results}

\subsection{Student Gender and Prior Student Attitudes and Perceptions of Class Discussion}

Student t-tests were conducted to compare women and men students' mean attitudes and perceptions of class discussion prior to the course from data collected in the pre-course survey. Men and women did not differ with respect to liking of or familiarity with class discussion, general evaluation of class participation, or typical or expected participation patterns as found in Table 1. However, there were two significant differences between women and men prior to the start of the course. Most notably, women students rated the question about typical comfort when engaged in active class participation lower than the men. Women rated their general satisfaction with class participation lower than the men as well. Thus, for the most part, men and women students began the course with similar attitudes about and perceptions of class discussion and class participation. However, women were less comfortable and less satisfied with their own class participation performance in prior courses.

Table 1. Pre-course survey mean comparisons between women and men students for key measures of attitudes and behaviors related to class discussion

\begin{tabular}{llll}
\hline & $\begin{array}{l}\text { Women Students } \\
\text { M(SD) }\end{array}$ & $\begin{array}{l}\text { Men Students } \\
\text { M(SD) }\end{array}$ & $\begin{array}{l}\text { GenderDifference } \\
\text { p-value }\end{array}$ \\
\hline Liking of Class Discussion & $5.20(1.37)$ & $5.10(1.25)$ & $\mathrm{ns}$ \\
Familiarity with Class Discussion & $5.79(1.22)$ & $5.68(1.19)$ & $\mathrm{ns}$ \\
Typical Participation Frequency & $4.81(1.43)$ & $4.73(1.36)$ & $\mathrm{ns}$ \\
Expected Participation Frequency & $5.00(1.19)$ & $5.08(1.16)$ & $\mathrm{ns}$ \\
Typical Comfort Participating & $4.63(1.55)$ & $4.92(1.41)$ & $<.05$ \\
General Evaluation of Class Participation & $4.94(1.28)$ & $4.90(1.28)$ & $\mathrm{ns}$ \\
Satisfaction with Class Participation & $4.64(1.36)$ & $4.89(1.25)$ & $<.05$ \\
\hline
\end{tabular}

\subsection{Effect of Student Gender on Percentage of Students Voluntarily Responding to Questions}

The evidence pertaining to the effect of student gender on voluntary responses to questions is based upon the examination of observations collected during two case sessions. The percentage of students who voluntarily responded during the discussion was analyzed using a full factorial repeated measures analysis of variance with three independent factors - student gender (women vs. men), cold-call environment (Lo CC vs. Hi CC) and observation period (case discussion 1 vs. case discussion 2). (Note 2) As shown in the ANOVA Results Table under Figure 1, there was no main effect due to gender differences on the percentage of students volunteering, holding the effects of cold-call environment and observation period constant. Further, the interaction between student gender and observation period is not significant. The ANOVA results do reveal a significant student gender by cold-call environment interaction, as shown graphically in Figure 1. While a significantly higher percentage of women and men students voluntarily participate in Hi CC than in Lo CC sections, further analysis of the increase reveals that the rate of change for women is significantly greater than for men $(t(429)=2.90, p=$ 0.004).

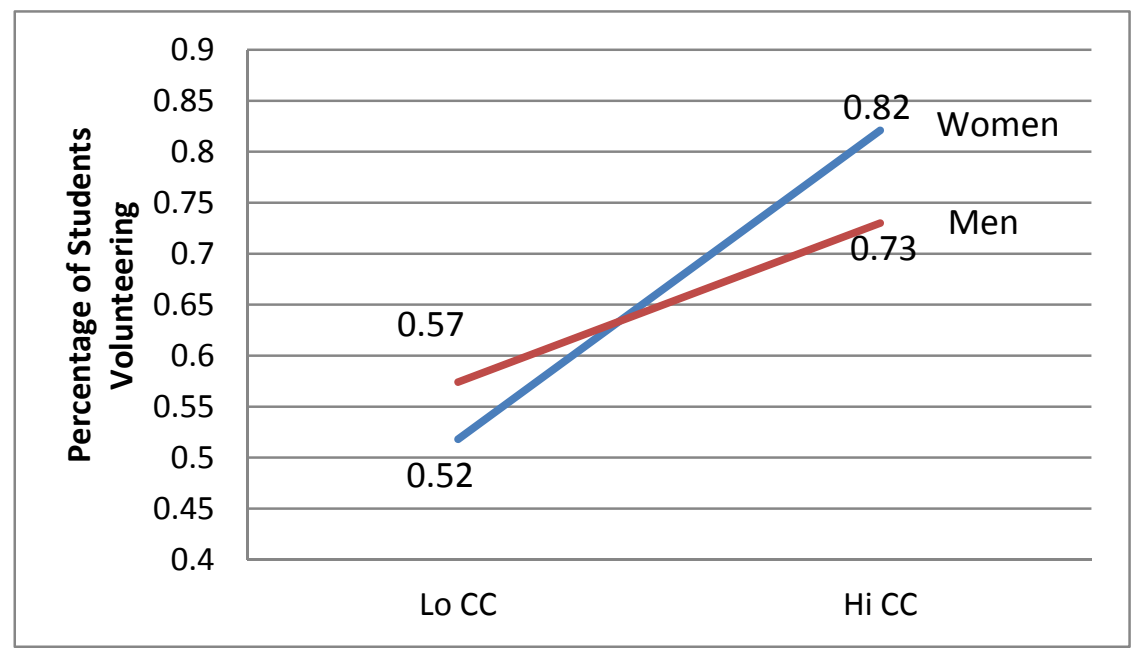

Figure 1. Gender by cold-call environment (CC) interaction: percentage of students volunteering 
ANOVA Results Table

\begin{tabular}{llll}
\hline Factor & df & F-statistic & p-value \\
\hline Gender & 1 & 0.312 & 0.577 \\
Gender x Observation & 1 & 1.388 & 0.239 \\
Gender x Cold-call Environment (CC) & 1 & 5.776 & 0.016 \\
Gender x Observation x CC & 1 & 0.198 & 0.656 \\
\hline
\end{tabular}

H1 focuses on the relationship between student gender and the percentage of students volunteering during class discussion. The results provide clear support that cold-calling differentially affects the percentage of women vs. men students voluntarily participating in class discussion, as the difference between Lo CC and Hi CC sections for women was significantly higher than for men. These results suggest women may be more sensitive to pedagogical approaches that encourage full participation in class discussion.

\subsection{Effect of Student Gender on Frequency of Student Voluntary Class Participation}

This section concentrates on the number of questions answered as compared to the prior section which focuses on the percentage of students participating in the discussions. Based on the observation data, the number of voluntary questions answered per student was computed.

\subsubsection{Class Participation Observations}

A full factorial repeated measures analysis of variance with three independent factors - student gender, cold-call environment and observation period - was used to analyze the number of volunteer questions answered per student. The table below Figure 2 contains the results of this analysis. We find only one significant effect due to student gender, a gender by cold-call environment interaction, as shown graphically in Figure 2 . This interaction indicates women students answer significantly more volunteer questions in the Hi CC sections than Lo CC sections $(\mathrm{t}(577)=6.346, \mathrm{p}=0.000)$; whereas, there is no significant increase in the number of volunteer questions answered by men when comparing Hi CC sections to Lo CC sections $(\mathrm{t}(851)=1.100, \mathrm{p}=0.272)$. Further, post hoc comparisons between men and women for the total number of volunteer questions answered shows a significant difference in the Lo CC sections $(\mathrm{t}(784)=2.904, \mathrm{p}<.01)$, but no difference in the Hi CC sections $(\mathrm{t}(350)=1.08, \mathrm{~ns})$.

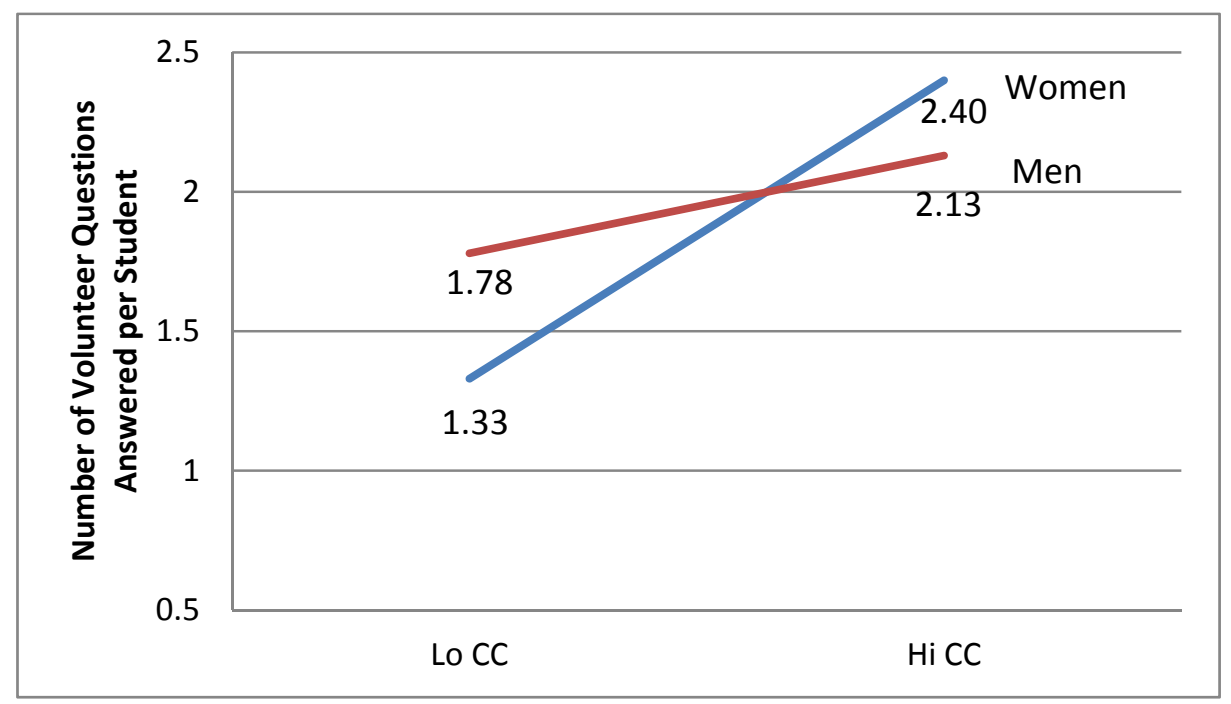

Figure 2. Gender by cold-call Environment (CC) interaction: number of volunteer questions answered per student

ANOVA Results Table

\begin{tabular}{llll}
\hline Factor & df & F-statistic & p-value \\
\hline Gender & 1 & 0.429 & 0.512 \\
Gender x Observation & 1 & 0.013 & 0.910 \\
Gender x Cold-call Environment (CC) & 1 & 6.966 & 0.008 \\
Gender x Observation x CC & 1 & 1.184 & 0.277 \\
\hline
\end{tabular}


Hypothesis 2 which relates student gender to the frequency of voluntary participation finds strong support from the analysis of the number of volunteer questions per student. The data suggest that when comparing participation between men and women across cold-call environments, the number of volunteer questions per student answered by women is significantly below that of men in Lo CC sections, but converges to men's in Hi CC sections.

\subsubsection{Instructor Cold-Calling Behavior}

The differences in behavior between men and women students discussed above raise the question of the effect of instructor behavior on student responses to class discussion. The following analysis addresses one aspect of instructor impact on class discussion: whether the instructor treats men and women students the same with respect to cold-calling during class discussion.

Because cold-called questions are initiated by the course instructor and directed at a particular student, analysis of these data can reveal bias if it is present. The number of cold-called questions per student was analyzed using the same approach as described above for the number of voluntary questions answered per student. In this case the repeated measures ANOVA did not reveal significant gender differences overall $(F(1,1130)=0.204$, $p$ $=.651)$. Further, there was no significant interaction between gender and cold-call environment $(\mathrm{F}(1,1130)=$ $0.029, \mathrm{p}=0.865)$. Therefore, the analyses indicate instructors in both Lo CC and Hi CC environments cold-called men and women students similarly.

\subsubsection{Summary of Findings Regarding Hypothesis 2}

In summary, when cold-calling is used frequently within a classroom environment, we see that voluntary class participation frequency increases for both men and women. Further, the significant gender by cold-call environment interaction in the observation data reveals women are more responsive to increased cold-calling. Their voluntary participation frequency increases from being significantly less than men in the Lo CC environment to being on a par with men in the Hi CC environment. Finally, instructors cold-called women and men students in a similar fashion; that is, instructor cold-calling did not favor one gender over the other. These results support research hypotheses 2 .

\subsection{Student Gender Effects on Comfort with Class Participation}

When cold-calling is used, more women and men students participate voluntarily. Given this result, we examined whether the effect of cold-calling on student comfort with class participation produced gender differences. As shown in Table 1, prior to the beginning of the course, there was a significant difference between men and women in ratings for comfort with class participation. Men students rated their comfort level significantly higher than women. This result raises concerns that women may be even more uncomfortable with class discussion in a $\mathrm{Hi} \mathrm{CC}$ environment which requires active class participation.

A post-course survey was administered during the last week of the course to assess student attitudes and perceptions of class discussion. To assess possible gender differences over time within the two classroom environments, we examined the effects of cold-call environment and survey time period (i.e., pre-course survey vs. post-course survey) on students' self-reported comfort with class discussion. Table 2 reports results from a repeated measures analysis of variance on student comfort, with the survey variables as the repeated measure and cold-call environment as the between-subject variable. None of the factors significantly affected student comfort ratings, including the main effect for gender difference as well as the interactions between gender and cold-call environment in the analysis.

Table 2. ANOVA results from self-reported student comfort with class discussion

\begin{tabular}{llll}
\hline Factor & df & F-statistic & p-value \\
\hline Gender & 1 & 2.253 & 0.134 \\
Gender x Survey Period & 1 & 0.000 & 0.996 \\
Gender x Cold-call Environment (CC) & 1 & 0.072 & 0.788 \\
Gender x Survey Period x CC & 1 & 0.041 & 0.840 \\
\hline
\end{tabular}

H3 deals with the effect of gender on student comfort with class discussion when cold-calling is used. The results provide no evidence that students' self-reported comfort with class discussion is significantly affected by student gender when cold-calling is used. 


\section{Discussion}

The pre-course survey data show men and women have similar attitudes and behaviors before the course with respect to participation in class discussions except for comfort participating and satisfaction with their participation. Women are less comfortable and less satisfied; these findings are consistent with earlier research on men and women in the classroom.

The differences in participation reported in prior literature might raise concern that women would react to a classroom environment with extensive cold-calling by withdrawing from the discussion even more and becoming even more uncomfortable. The results presented here provide evidence that this is not so.

From the observation data gathered during the course, we note that in the Lo CC environment, men tend to participate voluntarily more than women. Not only is the frequency of men's voluntary participation significantly higher than that of women's, but also a larger percentage of men than women participated voluntarily although this difference was not significant. Prior foundational research suggests instructors engage in various behaviors that reinforce the notion that women's participation is not expected and their contributions are not important (Hall, 1982, p. 3). Classrooms where instructors do not dynamically and purposefully engage all students in the discussion may serve to perpetuate these beliefs and discourage women's participation.

Cold-calling provides a means to improve the performance of both men and women in that increases the percentage of each who participates voluntarily. Further and perhaps most importantly, women's voluntary participation in Hi CC class environments increases from that found for women in Lo-CC classes and converges to the participation frequency of men in Hi-CC classes; that is, that they answer the same number of voluntary questions. Thus, in the Hi CC environment women are on a par with men in that they answer the same number of volunteer questions. Finally, both men and women respond similarly to cold-calling from the perspective of their comfort participating; increased cold-calling in the Hi CC environment did not make either group uncomfortable.

Cold-calling is a pedagogical strategy that might enhance equity and provide a more level playing field for women. When instructors use pedagogical strategies such as cold-calling, in which participation of all students is actively sought, the women's response reflects their pent-up demand. Women who may have wanted to participate but felt discouraged from doing so are now encouraged, thus embracing the opportunity; hence, the percentage of women participating increases more than men's.

\section{Limitations and Future Research}

The results presented above must be interpreted in light of the study's limitations. The data were gathered in a required management accounting course in a college of business. Thus, whether the results apply to other universities, other colleges such as engineering or law, or other disciplines is uncertain. Further, while this study examines the effects of cold-calling on men and women, the effects of cold-calling comparing other groups (e.g., international students vs. domestic students) should be explored.

Although earlier studies show increased participation in class discussions is associated with increased student learning (Dallimore et al., 2010) and cold-calling is associated with increased participation (Dallimore et al., 2013), the effect of cold-calling on objective measures of learning, such as final exam scores for individual students, should be directly examined.

\section{Summary}

This study examined whether cold-calling affects men and women students the same. It explored both the effect of cold-calling on the voluntary participation of these two groups and its effect on their comfort participating. Trained observers gathered data on whether instructors cold-called students or called on volunteers during two case discussions. In addition, data were gathered using pre- and post-course surveys of students' perceptions about and behaviors related to class discussions. The students in this study were sophomores enrolled in a required business course at a large, private research university.

The primary results indicated that in high cold-calling environments, a larger percentage of both men and women students participate voluntarily and women are on a par with men in that they answer the same number of volunteer questions. Further, both men and women respond similarly to cold-calling from the perspective of their comfort participating; increased cold-calling in the high cold-calling environments did not make either group uncomfortable. Differences observed between men and women's participation occurred in the low cold-calling environments as women answered fewer questions than did men.

This study makes a valuable contribution to the discussion-teaching literature especially as related to cold-calling. It does so by showing that instructors can cold-call in classes with men and women students and can help both 
groups improve their participation in class discussions without making them uncomfortable. Given that prior research has shown a strong link between class participation frequency and learning (Dallimore et al., 2010), it is imperative that all students be encouraged to participate in class discussion, not just those who are initially willing to volunteer.

\section{References}

Allan, E. J., \& Madden, M. (2006). Chilly classrooms for female undergraduate students: A question of method? The Journal of Higher Education, 77(4), 684-711. https://doi.org/10.1353/jhe.2006.0028

Arter, J., \& McTighe, J. (2001). Scoring rubrics in the classroom. Thousand Oaks, CA: Corwin.

Beekes, W. (2006). The 'Millionaire' method for encouraging participation. Active Learning in Higher Education, 7(1), 25-36. https://doi.org/10.1177/1469787406061143

Carnaghan, C., \& Webb, A. (2007). Investigating the effects of group response systems on student satisfaction, learning, and engagement in accounting education. Issues in Accounting Education, 22(3), 391-409. https://doi.org/10.2308/iace.2007.22.3.391

Coetzee, S. A., Schmulian, A., \& Kotze, L. (2014). Communication Apprehension of South African Accounting Students: The effect of Culture and Language. Issues in Accounting Education, 29(4), 505-525. https://doi.org/10.2308/iace-50850

Colbeck, C. L., Cabrera, A. F., \& Terenzini, P. T. (2001). Learning professional confidence: Linking teaching practices, students' self-perceptions, and gender. The Review of Higher Education, 24, 173-191. https://doi.org/10.1353/rhe.2000.0028

Cunningham, B. M. (2008). Using action research to improve learning and the classroom learning environment. Issues in Accounting Education, 23(1), 1-30. https://doi.org/10.2308/iace.2008.23.1.1

Dallimore, E. J., Hertenstein, J. H., \& Platt, M. B. (2010). Class participation in accounting courses: Factors that affect student comfort and learning. Issues in Accounting Education, 25(4), 613-629. https://doi.org/10.2308/iace.2010.25.4.613

Dallimore, E. J., Hertenstein, J. H., \& Platt, M. B. (2013). Impact of Cold-Calling on Student Voluntary Participation. Journal of Management Education, 37(3), 305-341. https://doi.org/10.1177/1052562912446067

Davis, B. G. (2009). Tools for teaching (2nd ed.). San Francisco, CA: Jossey-Bass.

Donovan, L. A., \& MacIntyre, P. D. (2004). Age and Sex Differences in Willingness to Communicate, Communication Apprehension, and Self-Perceived Competence. Communication Research Reports, 21(4), 420-427. https://doi.org/10.1080/08824090409360006

Ewens, W. (2000). Teaching using discussion. In R. Neff \& M. Weimer (Eds.), Classroom communication: Collected readings for effective discussion and questioning (pp. 21-26). Madison WI: Atwood Publishing.

Felder, R. M., \& Brent, R. (2008). The 10 Worst Teaching Mistakes. Chemical Engineering Education, 42(4), 201-202.

Fritschner, L. M. (2000). Inside the Undergraduate College Classroom: Faculty and Students Differ on the Meaning of Student Participation. The Journal of Higher Education, 71(3), 342-362. https://doi.org/10.1080/00221546.2000.11780826

Gilmore, T. N., \& Schall, E. (1996). Staying alive to learning: Integrating enactments with case teaching to develop leaders. Journal of Policy Analysis \& Management, 15(3), 444-457. https://doi.org/10.1002/(SICI)1520-6688(199622)15:3<444::AID-PAM8>3.0.CO;2-I

Hall, R. M. (1982). The classroom climate: A chilly one for women. Washington, DC: Project on the Status and Education of Women of the Association of American Colleges.

Krupnick, C. G. (1985, May). Women and men in the classroom: Inequality and its remedies. Journal of the Harvard Danforth Center, pp. 18-25.

Liang, N., \& Wang, J. (2004). Implicit mental models in teaching cases: An empirical study of popular MBA cases in the United States and China. Academy of Management Learning \& Education, 3(4), 397-413. https://doi.org/10.5465/amle.2004.15112545 
Micari, M., \& Drane, D. (2011). Intimidation in small learning groups: The roles of social-comparison concern, comfort, and individual characteristics in student academic outcomes. Active Learning in Higher Education, 12(3), 175-187. https://doi.org/10.1177/1469787411415078

Morford, Z. (2009). Class participation improves student performance. Behavior Analysis Digest International, 21(3), 9-10.

Quinn, A. (2010). An exploratory study of opinions on clickers and class participation from students of human behavior in the social environment. Journal of Human Behavior in the Social Environment, 20(6), 721-731. https://doi.org/10.1080/10911351003749102

Rocca, K. A. (2010). Student participation in the college classroom: An extended multidisciplinary literature review. Communication Education, 59(2), 185-213. https://doi.org/10.1080/03634520903505936

Sadker, M., \& Sadker, D. (1994). Failing at fairness: How America's schools cheat girls. New York: Charles Scribner's Sons.

Scollon, S., \& Bau, K. (1981). A model for making higher education more culturally sensitive. Conference of the National Association for Asian and Pacific American Education. Honolulu HI.

Stevens, D. D., \& Levi, A. J. (2005). Introduction to rubrics. Sterling, VA: Stylus.

Tatum, H. E., Schwartz, B. M., Schimmoeller, P., \& Perry, N. (2013). Classroom participation and student-faculty interactions: Does gender matter? Journal of Higher Education, 84(6), 745-768. https://doi.org/10.1353/jhe.2013.0036

Tsui, L. (2002). Fostering Critical Thinking Through Effective Pedagogy. The Journal of Higher Education, 73(6), 740-763. https://doi.org/10.1080/00221546.2002.11777179

Weaver, R. R., \& Qi, J. (2005). Classroom organization and participation: College students' perceptions. The Journal of Higher Education, 76(5), 570-600. https://doi.org/10.1353/jhe.2005.0038

Weimer, M. (2009). Cool Calling: A Creative Way to Start Discussions. The Teaching Professor, 23(10), 4-8.

\section{Notes}

Note 1. www.collegeatlas.org/top-degrees-by-sex.html

Note 2. For reporting clarity, only the gender main effect and the interactions between gender and the other factors are presented and discussed.

\begin{tabular}{|c|c|}
\hline Survey Variables & Survey Questions \\
\hline \multicolumn{2}{|l|}{ Pre-Course Survey } \\
\hline Liking of Class Discussion & How much do you like class discussion? $(1=$ Not at all, $7=$ Very much $)$ \\
\hline Familiarity with Class Discussion & How familiar are you with class discussion? $(1=$ Not familiar, $7=$ Very familiar $)$ \\
\hline Typical Participation Frequency & In most courses, I participate: $(1=$ Not at all, $7=$ Very frequently $)$ \\
\hline Expected Participation Frequency & In this course, I expect to participate: $(1=$ Not at all, $7=$ Very frequently $)$ \\
\hline & In general, when I participate in class discussions, I feel: $(1=$ Uncomfortable, $7=$ \\
\hline Typical Comfort Participating & Comfortable) \\
\hline General Evaluation of Class Participation & In general, the evaluation of my class participation has been: $(1=$ Low, $7=$ High $)$ \\
\hline Satisfaction with Class Participation & $\begin{array}{l}\text { In general, my satisfaction with my class participation is: }(1=\text { Not satisfied, } 7=\text { Very } \\
\text { satisfied) }\end{array}$ \\
\hline \multicolumn{2}{|l|}{ Post Course Survey } \\
\hline Comfort Participating in this Course & $\begin{array}{l}\text { In this course, when I participated in class discussions I felt: ( } 1=\text { less comfortable, } \\
7=\text { more comfortable) }\end{array}$ \\
\hline Observation Variables & Variable Definition \\
\hline $\begin{array}{l}\text { Percent M(F) Students Voluntarily Answering } \\
\text { Questions }\end{array}$ & $\begin{array}{l}\text { Total Number of M(F) Students Answering Volunteer Questions/Total M(F) Students } \\
\text { Present }\end{array}$ \\
\hline $\begin{array}{l}\text { Number of Volunteer Questions per M(F) Student } \\
\text { Number of Cold-Called Questions per M(F) Student }\end{array}$ & $\begin{array}{l}\text { Total Number of Volunteer Questions Asked to } M(F) / \text { Total } M(F) \text { Students Present } \\
\text { Total Number of Cold-Called Questions Asked to } M(F) / \text { Total } M(F) \text { Students Present }\end{array}$ \\
\hline
\end{tabular}




\section{Copyrights}

Copyright for this article is retained by the author, with first publication rights granted to the journal.

This is an open-access article distributed under the terms and conditions of the Creative Commons Attribution license (http://creativecommons.org/licenses/by/4.0/). 